\title{
APRENDIENDO DE LA COVID EN CANARIAS. EL PESCA-TURISMO COMO PROPUESTA DE DIVERSIFICACIÓN ECONÓMICA EN TENERIFE
}

\section{LEARNING FROM COVID IN THE CANARY ISLANDS. FISHING-TOURISM AS A PROPOSAL FOR ECONOMIC DIVERSIFICATION IN TENERIFE}

\author{
Pablo Díaz Rodríguez \\ Universidad de La Laguna. \\ padiaz@ull.edu.es \\ https://orcid.org/0000-0002-3568-716X \\ Alberto Jonay Rodríguez Darias \\ Universidad de La Laguna. \\ ajroddar@ull.es \\ https://orcid.org/0000-0003-4944-3737
}

Recibido/Received: 28/05/2021

Modificado/Modified: 04/10/2021

Aceptado/Accepted: 13/12/2021

\section{RESUMEN}

El turismo masivo de sol y playa ha mostrado una clara tendencia a la terciarización y al deterioro de la diversidad económica. Esta especialización puede derivar en una excesiva dependencia de la actividad turística, altamente expuesta a fenómenos imprevistos. El contexto de Canarias puede considerarse un caso paradigmático en este sentido, habiendo sufrido consecuencias devastadoras ante la crisis derivada de la COVID-19. La absorción del sector primario por el turismo ha afectado su capacidad de adaptación empeorando los impactos socioambientales de la pandemia. Entre las estrategias que pueden contribuir a repensar el modelo actual se plantea, en este trabajo, la implementación de un producto que articule la pesca tradicional con el turismo en Tenerife. La reciente Ley de Pesca de Canarias puede convertirse en una oportunidad para ampliar los niveles de resiliencia del destino, el empoderamiento y revitalización de la población pesquera.

\section{PALABRAS CLAVE}

Crisis turística, COVID, dependencia turística, Tenerife, turismo pesquero

\section{SUMARIO}

1. Introducción. 2. Aproximación al modelo turístico de Tenerife. 3. La crisis pandémica como punto de inflexión. 4. Pescaturismo: experiencia turística singular y apoyo a la pesca tradicional. 5. La población pesquera frente al turismo pesquero: oportunidades y limitaciones. 6. Conclusiones. 7. Bibliografía

\begin{abstract}
Massive sun and beach tourism has shown a clear trend towards outsourcing and deterioration of economic diversity. This economic specialization can lead to an excessive dependence on tourist activity, highly exposed to unforeseen phenomena. The context of the Canary Islands can be considered a paradigmatic case in this sense, having suffered devastating consequences from the COVID-19 crisis. The absorption of the primary sector by tourism has affected its adaptive capacity, worsening the socio-
\end{abstract}


environmental impacts of the pandemic. Among the strategies that can contribute to rethinking the current model, this work proposes the implementation of a product that articulates traditional fishing with tourism in Tenerife. The recent Canary Islands Fisheries Law may become an opportunity to expand the levels of resilience of the destination through economic diversification and the empowerment and revitalization of fishermen.

\section{KEYWORDS}

Tourism crisis, COVID, tourism dependency, Tenerife, fishing tourism

\section{CONTENTS}

1. Introduction. 2. Approach to the tourism model of Tenerife. 3. The pandemic crisis as a turning point.

4. Fishing tourism: unique tourist experience and support for traditional fishing. 5. The fishing population and fishing tourism: opportunities and limitations. 6. Conclusions. 7. References.

\section{INTRODUCCIÓN}

Los efectos de la pandemia global del COVID-19 están estrechamente ligados al desarrollo histórico del capitalismo (Cañada y Murray, 2021). La economía global se ha visto afectada, habiendo sido el turismo uno de los sectores más perjudicados. Los múltiples foros y debates sobre la urgencia de repensar el turismo, la importancia de implementar estrategias de gestión efectivas o la necesidad de diversificación económica en destinos dependientes frente a la vulnerabilidad del modelo turístico actual han quedado en agua de borrajas, mostrando su realidad retórica; no sólo por la incapacidad institucional de reaccionar frente a las consecuencias sociales del parón turístico provocado por la COVID, sino porque la tendencia general apunta a estrategias de recuperación basadas en la repetición del patrón histórico dominante desde la perspectiva apologética que mencionara Jafari (1994). Una trayectoria preocupante si tenemos en cuenta, además de los impactos obvios de la turistificación, que la colonización mundial del turismo se ha constituido como uno de los factores clave para la propagación planetaria del virus (Iaquinto, 2020).

Las evidencias señalan que aquellos destinos con mayor dependencia del turismo tienen mucho peores perspectivas de recuperación que aquellas con una economía con mayor diversificación (Cañada y Murray, 2021). En cambio, las presiones para reavivar las brasas turísticas se basan principalmente en la recuperación del sector empresarial y del consumo bajo el paradigma previo, lo que, lejos de devolvernos a la situación inicial, tiene luces de provocar un contexto de mayor desigualdad.

Entre las variables a reflexionar se encuentran los mecanismos de control para que el sistema turístico pueda revertir en beneficio social para las poblaciones de destino. Un modelo que evite la privatización y banalización al servicio de la demanda de los recursos públicos, que tenga en cuenta la capacidad biofísica de los destinos, potencie la calidad de vida de los anfitriones y respete su cotidianidad. Un modelo que empodere a las poblaciones locales y promueva la diversificación económica, que refuerce la recuperación de otros sectores y el reconocimiento la autoestima de sus profesionales, en el que el turismo contribuya a ello sin volverse indispensable. En definitiva, el ensayo de la crisis pandémica debería poner en el punto de mira un modelo responsable que contemple la resiliencia socioecológica de los destinos.

Entender el turismo como un hecho social en el que el contexto cultural y sociohistórico ha contribuido a generar patrones de vida insostenibles que han sido naturalizados, permite 
reparar en la posibilidad de generar dinámicas que puedan fomentar lo contrario. Para ello, el compromiso institucional y ciudadano es fundamental para resituar la cotidianidad y repensar las estructuras de poder implícitas en el turismo.

Los efectos negativos de la crisis pandémica han tenido una repercusión especialmente significativa en aquellas regiones mayormente especializadas y subordinadas al turismo. Canarias puede considerarse un destino con una gran dependencia turística, condicionada históricamente por la touroperación y la conectividad aérea y marítima. La incidencia de la pandemia en el sistema turístico canario ha sido catastrófica. A pesar de las primeras señales de brotes verdes, no es obvio que la circunstancia vaya a mejorar a medio plazo (cierre de empresas, despidos por finalización de los Expedientes de Regulación de Empleo [ERTE], precarización laboral, etc.).

La isla de Tenerife presenta un contexto turístico histórico aparentemente rentable y unos altos niveles de demanda y satisfacción que la sitúan entre los destinos europeos más competitivos. Sin embargo, la socioeconomía y el bienestar de sus habitantes muestra una estructura con cuotas diferenciales de poder muy marcadas y con visos de empeorar tras la situación pandémica.

Entre los aspectos de mejora sobre los que permite reflexionar el contexto actual, resalta la excesiva dependencia del sistema económico de la isla respecto al turismo y la mejora de su compatibilidad respecto a otros sectores productivos. La absorción del sector primario por el turismo y sus consecuentes repercusiones socioambientales sitúa el punto de mira sobre la diversificación económica y el empoderamiento local.

Este trabajo se enmarca en el proyecto "Inteligencia turística para un turismo marino responsable" cofinanciado por la Agencia Canaria de Investigación, Innovación y Sociedad de la Información y el Programa Operativo FEDER Canarias 2014-2020, en el contexto de una investigación en curso perteneciente a la línea de investigación de 'turismo pesquero y marino' del Instituto Universitario de Investigación Social y Turismo de la Universidad de La Laguna.

En él se hará una modesta contribución a este debate con el análisis de la propuesta de incorporación al destino de un producto de pequeña escala que aborda la articulación del sector turístico con el de la pesca tradicional y una aproximación a la percepción por parte de los pescadores profesionales de Fuerteventura y Tenerife, en base a 15 entrevistas en profundidad, en el contexto de las posibilidades que ofrece la reciente aprobación de la Ley 15/2019 de Pesca de Canarias.

\section{APROXIMACIÓN AL MODELO TURÍSTICO DE TENERIFE}

Existen muchas opciones a la hora de determinar el grado de éxito en el desarrollo de un determinado destino turístico. En el ámbito de este trabajo tomaremos como referencia los principales objetivos a los que debería tender desde una propuesta orientada a la sostenibilidad. De esta forma, suele entenderse que el éxito de un destino turístico depende de su grado de competitividad internacional (su atractivo para los turistas, ofrecer productos innovadores, gestionar adecuadamente los procesos de producción, etc.), promover el crecimiento económico para los diferentes agentes del destino, proporcionar experiencias satisfactorias y memorables para los turistas, su capacidad para potenciar la calidad de vida entre la población y su adecuada integración ambiental.

En primer lugar, en relación con la competitividad, Canarias constituye un destino de gran éxito internacional. En determinados indicadores clave, como el número de visitantes, 
pernoctaciones, fidelidad y duración de estancia media se coloca entre las primeras regiones europeas. Se trata además de un éxito sostenido durante varias décadas.

En el ámbito del archipiélago, la isla de Tenerife muestra los datos más destacados. En el gráfico 1 se muestra la evolución en el número de turistas entre 1950 y 2020, en el que se observa un descenso significativo como consecuencia de la crisis provocada por la pandemia COVID-19. En este último año de la serie recibió un total de 1.931 .943 turistas (fundamentalmente en el primer trimestre), frente a los 5.889.454 que había alojado en 2019.

Gráfico 1. Evolución de las llegadas de turistas a Tenerife.

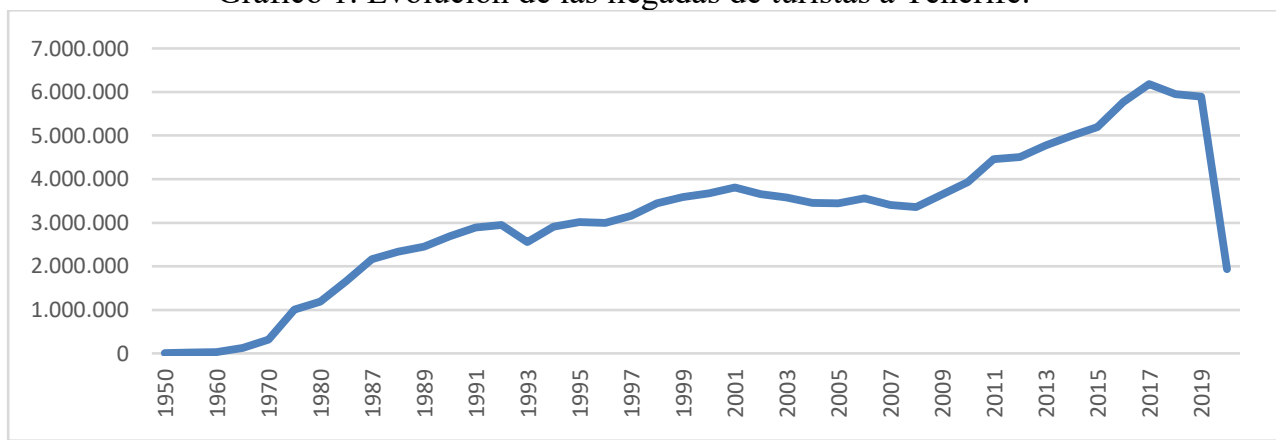

Fuente: elaboración propia a partir de Machado Carrillo, 1990 y datos del ISTAC (FRONTUR-Canarias).

Esta alta afluencia de visitantes se relaciona con el elevado número de plazas alojativas que se ofertan en la isla. En los gráficos 2 y 3 se muestra la evolución de éstas y de su tasa de ocupación media. En el año 2019 contaba con 137.723 plazas con una ocupación media anual del $80 \%$, datos que descendieron en 2020 a un total 68.275 plazas y una ocupación del $50,9 \%$. La caída en estos indicadores ya es notable, pero es mucho más significativa si tenemos en cuenta que durante casi la totalidad del primer trimestre del año la situación turística fue de total normalidad.

Gráfico 2. Evolución de la oferta de plazas turísticas en Tenerife.

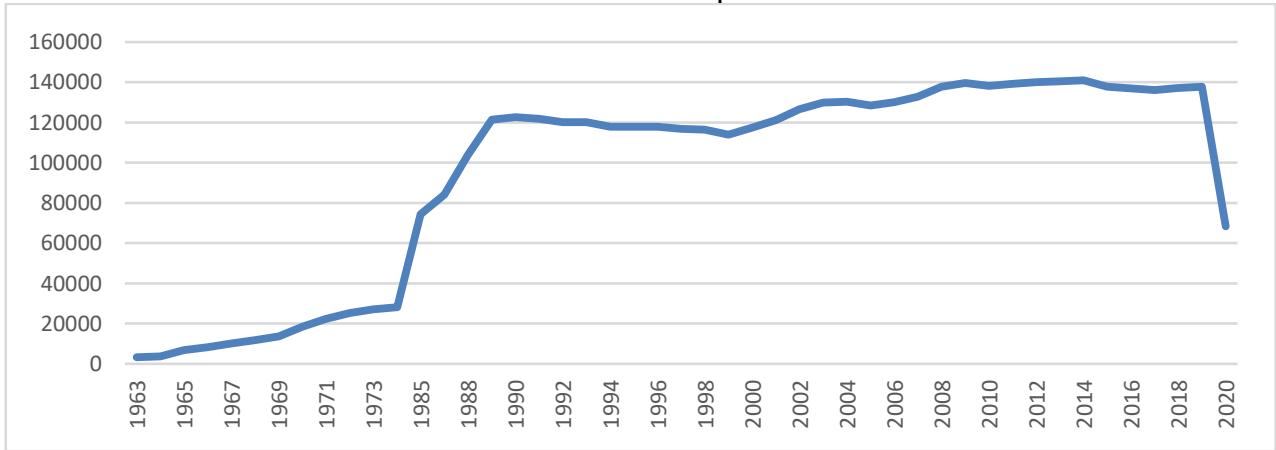

Fuente: elaboración propia a partir de Machado Carrillo, 1990 y datos del ISTAC (FRONTUR-Canarias).

Gráfico 3. Evolución de las tasas de ocupación turística en Tenerife. 


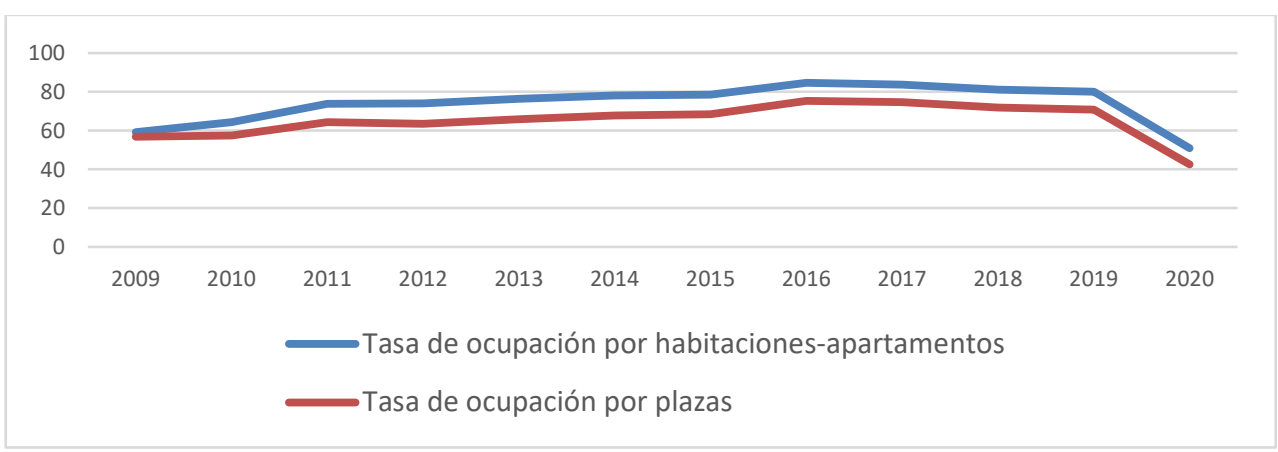

Fuente: Elaboración propia a partir de datos de la Encuesta de Alojamiento Turístico (ISTAC).

La rentabilidad de estas plazas alojativas también mostraba una tendencia creciente hasta la crisis sobrevenida por la COVID-19. La evolución de dos indicadores clave como los ingresos por habitación disponible (RevPAR) y la tarifa media por habitación mensual (ADR) (gráfico 4) indicaban un crecimiento sostenido, que se rompe en el año 2020 por la brusca caída de la demanda. Si bien el precio medio de la habitación mostró un comportamiento alcista, los ingresos por habitación descendieron significativamente.

Gráfico 4. Evolución de algunos indicadores de rentabilidad turística en Tenerife.

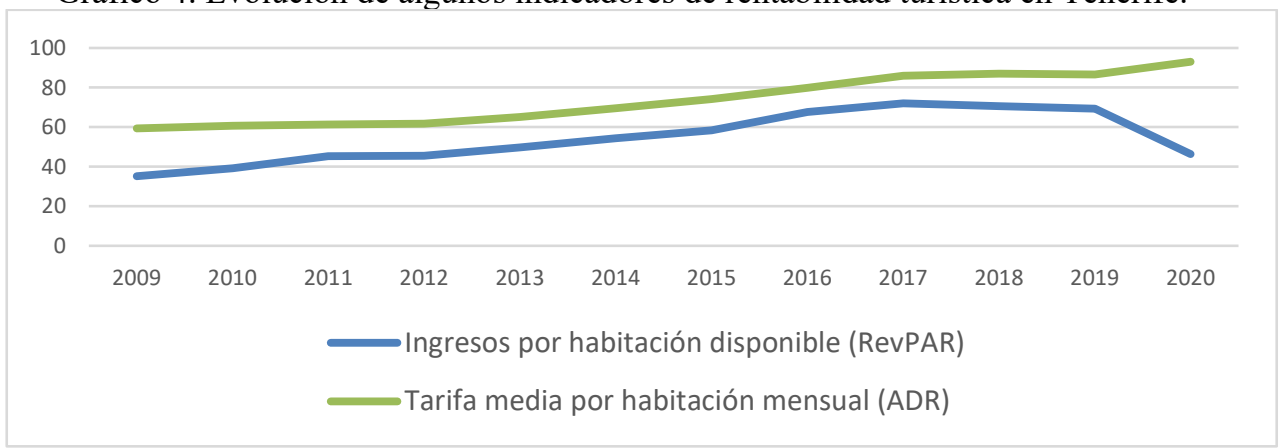

Fuente: Elaboración propia a partir de datos de la Encuesta de Alojamiento Turístico (ISTAC).

La influencia del turismo en la economía del destino es clave, ofreciendo vías de rentabilidad a multitud de agentes. De acuerdo con el último informe del estudio IMPACTUR Canarias, con datos relativos a 2018 el sector turístico aporta directa o indirectamente el 35,0\% del producto interior bruto del archipiélago. A estos datos habría que sumar los efectos inducidos del turismo en la economía regional, que potencialmente podrían ser de gran relevancia debido al conocido efecto multiplicador del turismo (sin contemplar las externalidades ni las alternativas). Precisamente el hecho de que este sector cuente con tanta influencia puede ser interpretado como una de las principales debilidades de la economía canaria; pues apunta a la dependencia de una actividad que, aunque ha mostrado gran estabilidad en las últimas décadas, tiene un alto grado de volatilidad potencial, está sometido a una fuerte competencia internacional y depende de flujos, actividades y variables de ámbito global sobre las que los agentes del destino pueden tener poca influencia. 
Entre estos elementos que se escapan del control puede destacarse la acción de los grandes intermediarios turísticos, en plena fase de reordenación por la incidencia de la pandemia. Además, las consecuencias de la crisis turística han revelado (y potenciado) las desigualdades sociales intrínsecas al modelo turístico dominante, en el que el reparto de los beneficios y los costes no es precisamente equitativo, habiendo afectado especialmente a aquellos destinos con mayor especialización y dependencia del turismo, como es el caso de Canarias (Murray y Cañada, 2021).

Por otro lado, parece que el sistema turístico de Tenerife está cumpliendo adecuadamente con el objetivo de ofrecer experiencias satisfactorias y memorables entre los visitantes. De acuerdo con datos de la Encuesta de Gasto Turístico de Canarias (Instituto Canario de Estadística, ISTAC), los turistas puntuaron su satisfacción respecto a su viaje con una media de 8,9 sobre 10 en 2020. Mostrando un índice de fidelidad con el destino relevante; el 41,2\% de los turistas que visitaron Tenerife en 2019 ya lo habían hecho alguna vez en los últimos 5 años. De hecho, el destino cuenta con lazos importantes de fidelidad con turistas de sus mercados emisores tradicionales (Inglaterra, Alemania y España), de los que depende la mayoría de su demanda. La estrecha conexión con estos mercados constituye una fortaleza del destino, todo parece apuntar a que esta demanda se reactivará sin complicaciones relevantes en cuanto se controle la crisis pandémica. De hecho, el atractivo de Canarias como destino turístico sobrepasa estos mercados tradicionales. Recientemente, una encuesta a más de 600.000 turistas de 192 países elaborada por European Best Destinations tuvo como resultado que Canarias fue el décimo destino más elegido ante la pregunta "¿A dónde le gustaría ir de vacaciones en Europa tan pronto como sea seguro viajar?”.

Son muchas las variables que pueden tenerse en cuenta para intentar determinar la calidad de vida de la población residente en un determinado territorio. La densidad de población puede ser una variable básica a este respecto. La isla de Tenerife tiene actualmente unos 928.604 habitantes, lo que implica una densidad de población de 456,54 habitantes por kilómetro cuadrado. Si tenemos en cuenta que el $48,6 \%$ de la superficie de la isla se encuentra bajo alguna figura de protección ambiental, esta densidad de población se incrementa significativamente; especialmente en determinadas áreas urbanas y turísticas. La tendencia del último siglo ha sido de claro crecimiento, con una evidente vinculación al desarrollo de la industria turística. A esta población residente en la isla hay que sumar la 'población turística equivalente', que en el caso de Tenerife se correspondía en 2019 con 97.493 personas (con un descenso en 2020 hasta las 29.008 de media anual).

La evolución poblacional y el crecimiento turístico de la isla han conllevado una importante transformación del territorio. El impacto ambiental de las infraestructuras directamente orientadas a la explotación turística está concentrado en determinados microdestinos turísticos claramente delimitados; pero a estas infraestructuras habría que sumar la transformación ambiental motivada por el crecimiento en la superficie urbanizada (originada en gran parte directa o indirectamente por el crecimiento turístico), especialmente conflictiva por la tendencia hacia un modelo de urbanización extensiva (horizontal) que ha vivido la isla en los últimos 60 años. Este modelo de crecimiento complementado con una política de protección de determinados espacios considerados especialmente valiosos por sus valores ambientales ha dado lugar a un sistema singular, en el que prácticamente la mitad del territorio se integra en la Red Canaria de Espacios Protegidos bajo diferentes figuras de protección ambiental, y en la superficie restante se han ido desarrollando proyectos intensivos de desarrollo masivo. Esta forma de gestión y planificación territorial está íntimamente relacionada con el devenir del turismo en la isla. La protección ambiental estuvo motivada por la preocupación ante la evidente transformación territorial derivada, en 
gran parte, del desarrollo turístico, pero también por la intención de dotar a la industria turística de espacios de gran valor paisajístico para su consumo estético (Rodríguez Darias, 2011). Canarias cuenta con una huella ecológica vinculada al índice de presión turística socioambiental, muy por encima de la media mundial (6,52 gha., frente al 2,3 gha. per cápita respectivamente), con impactos directos sobre sus recursos naturales, como el déficit hídrico, la producción de residuos y contaminación, el consumo energético o abandono de actividades bioproductivas (Fernández-Latorre y Díaz del Olmo, 2011).

Además de la densidad poblacional y la posible degradación ambiental, existen multitud de efectos con los que un modelo de turismo masivo puede afectar a la calidad de vida de la población. Sin ser el objetivo de este trabajo detallarlos, deberíamos tener en cuenta los efectos de la inflación, las infraestructuras, el acceso a determinados productos, la transformación del patrimonio cultural, los conflictos de apropiación del espacio público, la oferta cultural y de ocio, la mercantilización de prácticas culturales, etc.

Las formas en que estas dinámicas impacten en la calidad de vida de la población son contextuales; están sujetos a múltiples variables y adaptaciones culturales. Son muchos los modelos teóricos que han intentado formalizar las correspondencias entre la presión turística, poblacional y la irritación de la población (en el ámbito turístico podemos destacar la propuesta pionera de Doxey [1975]). De hecho, durante la última década, el análisis de los movimientos y discursos en torno a los procesos de turistificación y turismofobia ha sido un ítem muy relevante en el ámbito de la sociología y antropología del turismo.

En el caso de Tenerife existe aún escasa literatura sobre las reacciones sociales a los impactos del turismo. Comienzan a visibilizarse las contestaciones locales a los procesos de turistificación vinculados a desahucios y gentrificación (García-Hernández et al., 2020; García-Hernández y Ginés de la Nuez, 2020; Díaz-Rodríguez et al., 2018), la precariedad laboral, la desigualdad social relacionada con los beneficios y costes del turismo o el poder de los intereses privados en una gestión del espacio público en la que la cotidianidad de las poblaciones locales queda en un segundo plano frente a su adecuación a las demandas turísticas (Delgada, 2017; García-Herrera y Sabaté Bel, 2005). En cualquier caso, parece que estos discursos tienen menos presencia (o se les ha prestado menos atención) que en otros destinos turistificados.

La influencia directa e indirecta del turismo en la economía canaria (35\% del PIB) y su repercusión en el empleo (40,4\%), coloca al archipiélago en una situación de dependencia que bien podría argumentar, consciente o inconscientemente, la construcción de discursos legitimadores de la actividad turística. Aunque también podría plantearse que la alta afluencia turística y el desarrollo poblacional aún no se perciben como generadores de tensiones significativas en este caso concreto (a diferencia de otros destinos masivos). Otro factor puede ser el alto grado de clientelismo y 'caciquismo' local, derivada en parte de una marcada desigualdad social (fomentada por el turismo y acrecentada tras la crisis pandémica), que condiciona la visibilidad de las reacciones sociales en contra del statu quo (García-Herrera y Sabaté Bel, 2005).

El modelo productivo de Tenerife está claramente orientado al sector servicios, con importante relevancia del turismo en su composición. En el gráfico 5 se muestra la evolución de la distribución de la población empleada por sectores de actividad. Si bien el hecho de que el desarrollo de la actividad turística precise de productos y servicios relacionados con otros sectores productivos ha argumentado que se considere su efecto multiplicador (Prados Pérez, 2001) en producción, renta, ingresos estatales, empleo (Cruz Vareiro y Cadima Ribeiro, 2007; Gelan,2003, entre otros) y consumo, parece que el caso concreto de este 
destino existe un margen importante para la implementación de actividades productivas en otros sectores.

Gráfico 5. Distribución del porcentaje de población ocupada por sectores de actividad en Tenerife.

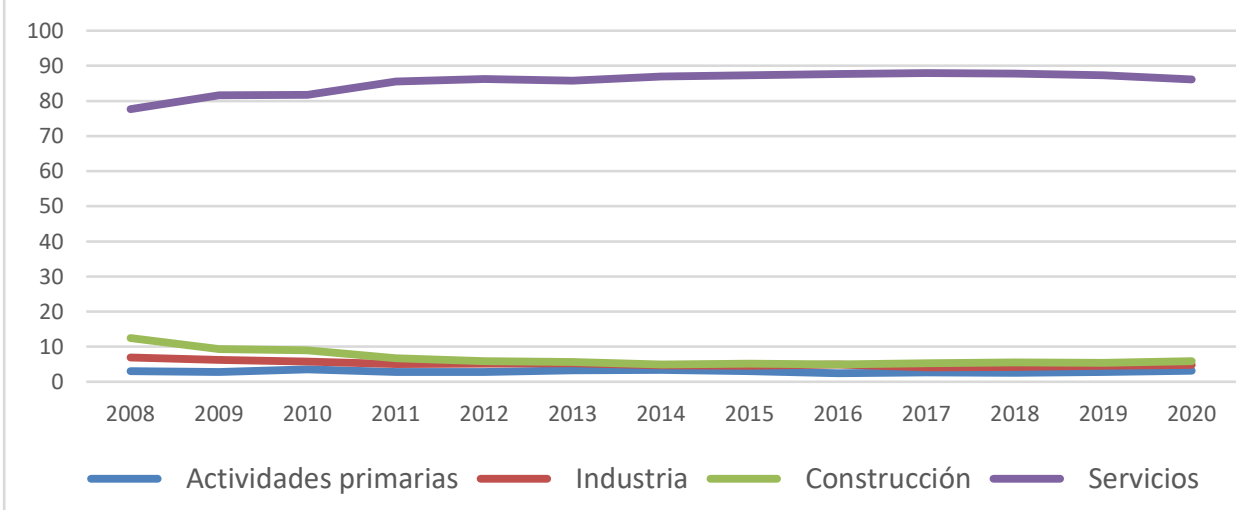

Fuente: elaboración propia a partir de datos de la Encuesta de Población Activa (EPA).

En cualquier caso, la actividad turística también genera competencia en cuanto a recursos y mano de obra con otras actividades (fundamentalmente primarias) hasta el punto de suplantarlas (Hampton, 2005, entre otros). Esto implica el tránsito de actividades productivas estabilizadas a otras normalmente inestables y dependientes del exterior. Las políticas relacionadas con la celebración de ERTEs en la isla han facilitado que los niveles de paro no se incrementen radicalmente, habiéndose mantenido la 'tasa media de paro' en la línea de años anteriores, al menos durante el primer trimestre de 2021.

Resulta paradigmático que un sistema turístico como el de Tenerife (masivo, con aparente tendencia a la rentabilidad, una demanda con altos niveles de satisfacción y entre las regiones europeas más competitivas en el ámbito turístico) cuente con una tasa del desempleo más o menos estabilizada (no coyuntural) entre el 18,79\% y el 34,76\% durante la última década. Este dato se coloca entre los peores de Europa y supone una evidencia importante de que el sistema insular no puede considerarse exitoso en relación con uno de los aspectos clave para determinar la calidad de vida de la población. De hecho, según el 'Índice de Calidad de Vida en España', Canarias se sitúa entre las cinco comunidades con peor calidad de vida del país (Statista, 2021), siendo la variable de afección turística un factor clave para ocupar dicha posición (González et al., 2010, 2011; Martín y Mendoza, 2012).

\section{LA CRISIS PANDÉMICA COMO PUNTO DE INFLEXIÓN}

La incidencia de la pandemia en el devenir turístico canario ha sido devastadora. En el momento actual (abril de 2021), los datos son ligeramente mejores respecto a los últimos meses, pero aún distan mucho de los resultados anteriores a la COVID. Como muestra de ello, en la tabla 1 puede observarse el número de instalaciones alojativas abiertas en la isla, su tasa de ocupación y el número de turistas recibidos en marzo de 2021 y su comparación con las mismas variables relativas a marzo de 2019. 
Tabla 1. Comparativa de algunos datos turísticos entre marzo de 2019 y de 2021

\begin{tabular}{|l|c|c|}
\hline & Marzo de 2019 & Marzo de 2021 \\
\hline Turistas alojados & 525.988 & 93.756 \\
\hline Establecimientos alojativos abiertos & 429 & 138 \\
\hline Plazas ofertadas & 138.664 & 53.533 \\
\hline Tasa de ocupación por habitación & $84,15 \%$ & $29,16 \%$ \\
\hline
\end{tabular}

Fuente: Elaboración propia a partir de datos de la Encuesta de Alojamiento Turístico (ISTAC)

Debido a determinadas políticas de protección social (fundamentalmente la aplicación de ERTEs), la influencia de esta dinámica en las estadísticas del paro, ha sido limitada, si bien se plantea un futuro incierto en el que muchos de sus beneficiarios podrían acabar desempleados. En cualquier caso, el acceso a estas herramientas ha sido diferencial en función del rango laboral, además de que la circunstancia actual ha provocado una disminución salarial con especial incidencia en los empleos de mayor precariedad, a lo que habría que sumar el importante impacto sufrido en el trabajo informal asociado al turismo (Cañada y Murray, 2021). Las previsibles dificultades del sector para alcanzar las cuotas previas a la pandemia y la futura competencia laboral pueden derivar en una acentuación de la precarización del trabajo en la que mayoritariamente se ha estructurado el turismo históricamente (Cañada, 2019).

Los entornos urbanos, ciertos espacios que concentran visitantes (como algunas playas, áreas naturales, etc.) y, especialmente, las áreas de alojamiento turístico han sufrido una radical transformación durante este año de crisis pandémica. La ausencia de turistas se hace evidente y queda por determinar las implicaciones que esta circunstancia pueda tener en las representaciones y conceptualizaciones de los residentes sobre los turistas y la actividad turística en sí. Se abre una interesante línea de investigación sobre las implicaciones culturales de esta circunstancia, que pudiera afectar a un amplio abanico de aspectos: expectativas de vida, reorientación de carreras profesionales, reconversión de núcleos turísticos, reordenación de servicios, revitalización de actividades productivas, formas de adaptación, estructura social o migraciones. El establecimiento de proyecciones relacionadas con estos procesos en el momento actual es demasiado complicado y los niveles de incertidumbre son aún elevados, pero sí que tenemos evidencias de que los residentes están incrementando el uso de determinados espacios que se consideraban apropiados por la industria turística (especialmente en el caso de determinadas playas). Si hasta ahora podíamos observar que la población residente desarrollaba determinadas estrategias para mantener libres de turistas determinados lugares (como ciertos restaurantes, playas, entornos de carácter religioso, espacios naturales, etc.) con el fin de liberar tensiones sociales producidas por la constante exposición a los otros, en la actualidad estas propuestas carecen de sentido.

Sin lugar a duda, la baja afluencia turística también ha afectado a la experiencia de los turistas. En un destino masivo como Tenerife, es difícil determinar con certeza si el descenso en el número de turistas puede ser percibido de manera positiva o negativa por los visitantes. Dependiendo del tipo de actividad a desarrollar, la presencia masiva de personas puede 
aportar sensaciones positivas o negativas a la experiencia (pensemos, por ejemplo, las diferencias en este sentido respecto a la asistencia a un gran concierto, la visita a un santuario natural, un parque de atracciones o un museo). En todo caso, los datos de la 'encuesta de gasto turístico' desarrollada por el Instituto Canario de Estadística nos muestran que los niveles de satisfacción media entre los turistas que visitan la isla son muy similares en los meses antes de la pandemia y la actualidad (una media de 8,7 sobre 10 en 2019 frente a 8,9 en el último dato en relación con la satisfacción y un 8,9 frente a 9,4 respecto a si consideraría recomendar la visita a Tenerife). Asimismo, como se ha mencionado, parece que la demanda potencial del destino no se ha visto afectada y, en principio, podrían obtenerse unos valores de afluencia similares a momentos anteriores a la crisis pandémica en cuanto se obtengan unos niveles adecuados de inmunidad de grupo y se reabra el turismo internacional. Aunque también es cierto que el modelo turístico podría sufrir cambios relevantes debido a modificaciones en el sistema empresarial de intermediación global, el posible cierre de infraestructuras alojativas, la más rápida incorporación de determinados destinos, etc.

Por otra parte, aunque se trate de una crisis motivada por la imposibilidad del viaje y no por la debilidad del destino, la situación actual supone una circunstancia sin precedentes para analizar el modelo turístico y plantear su reconfiguración. Muchas son las voces que han propuesto aprovechar este momento para apostar por un modelo turístico más sostenible a nivel global, observando en este parón una oportunidad para repensar estrategias, bajo la argumentación de que esta situación supone sólo una muestra de otras que podrían sucederse cuando los niveles de afectación ambiental empeoren. De esta forma, se nos ofrece una oportunidad única para aprender colectivamente y abrir la perspectiva a nuevos modelos (Gösslinget al., 2020). Aunque no está clara la transcendencia de este tipo de discursos, parece que más bien desde la industria turística se tiende a presionar a las autoridades para acelerar los procesos de reapertura del turismo internacional y a motivar un modelo de consumo que reproduzca el sistema anterior (Rodríguez Darias, 2020).

Como se ha mostrado, el destino turístico de Tenerife muestra luces y sombras. Entre los aspectos a mejorar podríamos destacar la excesiva dependencia del sistema económico local respecto a este sector productivo; teniendo en cuenta las posibilidades que, con una gestión adecuada, se le atribuyen al turismo como multiplicador de la economía, parece evidente que existe amplio margen de mejora para que el turismo se convierta realmente en un motor de impulso para otros sectores productivos (fundamentalmente de carácter primario). También podría aprovecharse el momento actual para repensar la idoneidad del volumen de afluencia de turistas y la cantidad de plazas alojativas que deberían ofrecerse. Partiendo de que algunas de las infraestructuras que han cerrado en el contexto de la pandemia ofrecen niveles de innovación y rentabilidad inferiores a gran parte de las que se han mantenido abiertas, quizá pudiera escalarse la oferta alojativa y optar por un cambio de utilidad de algunas de estas infraestructuras. Por otro lado, se ha observado que el tejido vecinal ha favorecido la resiliencia de los comercios locales frente al resto (González-Morales et al., 2020), por lo que un futuro modelo responsable debería pasar necesariamente por estrategias de empoderamiento local. Dicho empoderamiento implica necesariamente el fomento de una participación efectiva en la toma de decisiones que favorezca el control de las poblaciones de destino sobre sus propias vidas y la comprensión de su entorno, a través de "un proceso continuo intencional centrado en la comunidad local, que involucre respeto mutuo, reflexión crítica, cuidado y colaboración grupal, a través del cual las personas que carecen de una parte igual de los recursos valorados obtengan un mayor acceso y control sobre los mismos" (Cornell Empowerment Group, 1989: 2). 
Las posibilidades son muchas y deberían ser objeto de debate académico, político y social. Entre las tácticas que podrían orientarse/contribuir a esta mejora, en las siguientes páginas se plantea la posibilidad de contemplar la implementación de un producto a pequeña escala que articule la pesca tradicional con el turismo. Desde una perspectiva responsable, la reciente Ley 15/2019 de Pesca de Canarias puede convertirse en una oportunidad de diversificación económica que empodere y revitalice la población pesquera, con amplios beneficios para la sociedad y el territorio.

\section{PESCA-TURISMO: EXPERIENCIA TURÍSTICA SINGULAR Y APOYO A LA PESCA TRADICIONAL}

Entre las estrategias resilientes que se pueden implementar para construir productos responsables que no generen dependencia en los destinos, el turismo pesquero, aquel que compatibiliza la actividad pesquera profesional con actividades turísticas basadas en la apreciación y disfrute de sus prácticas tradicionales, se muestra con gran potencial. Una gestión adecuada que evite la banalización de los referentes de identificación simbólica relacionados con la actividad o la absorción y performativización de la misma por los intereses turísticos, podría repercutir en la recuperación de un sector pesquero que se beneficie de la actividad turística sin abandonar su producción primaria. La diversificación económica de este modelo no solo puede generar diversos beneficios socioecológicos, sino que favorece los mecanismos de resistencia socioeconómica ante posibles impactos sobrevenidos que afecten las dinámicas del sistema turístico.

El medio marino representa un recurso clave para multitud de actividades productivas. En el ámbito turístico muestra alta capacidad para proporcionar experiencias de gran valor. La percepción social de los beneficios sobre el bienestar (Kaplan, 1995; Fuller et al., 2007) y la salud (Mitchell y Popham, 2008; Serensinhe, 2015) de la interacción con la costa y el medio marino, junto con la rentabilidad económica que el turismo marino puede suponer (Dimmock y Musa, 2015), ha hecho de este medio un bien estratégico para los propósitos de diversificación de economías tradicionales, así como la renovación y mejora de los niveles de rentabilidad de destinos turísticos.

Las diferentes formas de inclusión de la actividad pesquera en el turismo se presentan como estrategias de diversificación económica responsable con la cultura y el territorio a partir de la puesta en valor de las actividades productivas históricas de los colectivos de profesionales del mar. Bien gestionado, puede convertirse en una estrategia efectiva que reduzca los riesgos de una excesiva terciarización de los destinos, abriendo las posibilidades de resistencia socioeconómica ante vicisitudes imprevistas que desestabilicen el sector turístico. Como herramienta de diversificación económica y empoderamiento del sector pesquero, puede suponer una herramienta que potencie la resiliencia de los destinos ante fenómenos inesperados como la COVID-19.

Tratando de abarcar las diversas acepciones mencionadas en el marco legal de los distintos ámbitos territoriales españoles donde se aplica, Moreno Muñoz define estas formas de turismo como aquellas

"actividades desarrolladas en un entorno del litoral, a bordo o fuera de las embarcaciones pesqueras, con el fin de diversificar la economía y poner en valor una singularidad que incida positivamente en los sectores pesquero y de servicios en zonas costeras tradicionales mediante contraprestación económica, para difundir la 
cultura marinera, sus tradiciones, el trabajo en el medio marino y en las instalaciones portuarias, el patrimonio material e inmaterial asociado y el modo de vida de los pescadores" (2018:391).

Aunque con resultados heterogéneos según las localidades en las que se han implementado, podemos encontrar aplicaciones exitosas en América, Asia y Europa (Pardellas y Espejo, 2013; Moreno Muñoz, 2018). La experiencia europea muestra que los profesionales vinculados al turismo pesquero suelen centrarse en actividades de tierra, como las gastronómicas o las visitas a fábricas y museos, frente al menor uso, sobre todo en los casos españoles, de aquellas relacionadas con el empleo de las embarcaciones pesqueras (CETMAR, 2010; Pardellas, 2011).

Existen numerosos casos de productos turísticos relacionados con la pesca a nivel internacional. En Europa pueden destacarse casos de éxito, como el italiano, que han servido de empuje y ejemplo para otros países que se han aprovechado de su experiencia (Molina García, 2013). Frente a otro tipo de negocios turísticos, las asociaciones pesqueras que complementaban sus rentas con el turismo tienen la posibilidad de continuar con sus actividades productivas, reduciendo el impacto del parón turístico generado por la COVID19. En España, la histórica falta de normativa ha bloqueado su implementación hasta la promulgación de la Ley 33/2014, de 26 de diciembre, de Pesca Marítima del Estado (salvando regulaciones regionales; la primera, la Ley 11/2008, de 3 de diciembre de Pesca de Galicia sobre turismo mariñeiro). La presión de las organizaciones de pesca profesional ha jugado un papel crucial en la introducción paulatina de esta actividad, que poco a poco parece que comienza a implementarse, con mayor o menor éxito, en ciertas localidades (Pardellas y Padín, 2013).

Las posibilidades de aprovechamiento de las actividades pesqueras como experiencia turística son muy variadas, incluyendo productos en tierra y en el mar, activas y pasivas, relacionadas con la tradición o de vanguardia tecnológica. En la referida Ley 33/2014, estas posibilidades se engloban en el concepto turismo pesquero o marinero, definido como una

"actividad desarrollada por los colectivos de profesionales del mar, mediante contraprestación económica, orientada a la valorización y difusión de las actividades y productos del medio marino, así como de las costumbres, tradiciones, patrimonio y cultura marinera, que por ello trasciende la mera actividad extractiva y comercial".

En la ley se hace referencia explícita a las actividades de pesca-turismo y turismo acuícola como dos tipologías particulares dentro de la gran variabilidad posible. El turismo acuícola se relaciona con la desarrollada por los profesionales de la acuicultura para valorizar y difundir su actividad y productos, mientras que el pesca-turismo se presenta como un "tipo de actividad de turismo pesquero o marinero desarrollada a bordo de embarcaciones pesqueras por parte de profesionales del sector, mediante contraprestación económica, que tiene por objeto la valorización y difusión de su trabajo en el medio marino, en la que los turistas embarcados no podrán ejercer la actividad pesquera". Dadas sus características, se entiende que el pesca-turismo precisa una normativa específica para su desarrollo.

Estos tipos de producto se muestran como modelos con grandes ventajas para el medio y la socioeconomía de los lugares en los que se implementan (Herrera et al., 2018). El potencial reside en su capacidad para complementar las rentas de las personas que se dedican a la pesca y apoyar su diversificación económica, favoreciendo cultural, ambiental y económicamente los entornos en los que se llevan a cabo. Especialmente positivo puede 
resultar en el caso del pesca-turismo, en el que pescadores profesionales utilizan sus embarcaciones para transportar turistas que desean conocer la costa, observar las faenas pesqueras de primera mano o participar de ellas, con la posibilidad de consumir posteriormente sus capturas (Pascual, 2004), con importantes implicaciones en la puesta en valor del mundo de la pesca y la disminución de la presión en las pesquerías.

La actividad, sin embargo, se enfrenta a un peligro ya conocido: su resimbolización y adecuación idealizada en base a un imaginario acorde con las demandas turísticas de autenticidad (Díaz, 2015). Las dinámicas de rentabilización del territorio tienen el poder de adaptar su potencial socioambiental a intereses específicos, adecuando prácticas y personas a un escenario performativo que se traduzca en experiencia turística (Rodríguez Darias et al, 2011). La singularidad y el exotismo que puede brindar el pesca-turismo corre el riesgo de petrificarse en un pasado idealizado proyectado de acuerdo con las expectativas neoliberales de privatización de recursos (Harvey, 2011), más que como estrategia para potenciar la conservación o la calidad de vida. Por otro lado, hay que contemplar las contingencias derivadas de la incorporación a la actividad turística de un elenco de actores que, si bien cuenta con formas de organización histórica a través de las cofradías, precisan de formación específica relacionada con las estrategias de comercialización turística, proyección de imagen, previsión de impactos, calidad de servicio y trato a los visitantes.

En el caso de Canarias, los esfuerzos por compatibilizar el turismo con la pesca artesanal llevan años en el tintero. Después de más de una década de debate sobre el Anteproyecto de Ley de Pesca Marítima, Marisqueo y Acuicultura de la Comunidad Autónoma de Canarias de septiembre de 2009, la proposición ha quedado obsoleta. En lo referente al turismo pesquero, y específicamente al pesca-turismo, el anteproyecto tomaba como modelo la vigente ley gallega sobre turismo mariñeiro (Ley 11/2008, de 3 de diciembre) ya mencionada, asumiendo literalmente su definición.

Tras el fracaso de esta iniciativa, la Consejería de Agricultura, Pesca y Aguas del Gobierno de Canarias anunció en 2018 una propuesta de decreto para la incorporación del turismo pesquero en la Ley de Pesca Canaria, con la intención expresa de incentivar actividades complementarias vinculadas al turismo, que revalorizasen el oficio de los trabajadores del mar y posibilitara la complementariedad de sus rentas. El resultado de la iniciativa ha sido la promulgación de la reciente Ley 15/2019 de 2 de mayo, que modifica la Ley 17/2003 de 10 de abril de Pesca de Canarias.

La argumentación incluida en el preámbulo de esta ley alude a su necesidad en base a la histórica demanda del sector pesquero por la regulación a escala regional de actividades económicas complementarias vinculadas a la pesca y la acuicultura, así como al hecho de que esta posibilidad ya se había abierto a nivel estatal con la Ley 33/2014, de Pesca Marítima del Estado. Desde el sector se alude, desde hace décadas, a la amplia representación de técnicas de pesca artesanal, la importante afluencia de turistas (prácticamente ininterrumpida) y las óptimas condiciones climatológicas que permiten el desarrollo de la actividad durante todo el año en determinadas zonas del archipiélago como aspectos que justifican el alto potencial de estas actividades en Canarias (IEO, 2013). La búsqueda histórica de estrategias de diversificación de los pescadores canarios ha sido justificada por los propios Grupos de Acción Costera canarios (GAC Fuerteventura, 2021). Durante los años cincuenta y sesenta, era habitual que, de manera esporádica, los fines de semana y en periodos vacacionales, los pescadores profesionales embarcaran a turistas y locales para sumar a sus retribuciones. Actualmente, muchos pescadores utilizan el alquiler de viviendas, la explotación de bares o restaurantes donde se ofrece su pescado fresco para aumentar sus 
ingresos, si bien, ambos servicios carentes de la potencialidad del valor añadido que podría tener su oferta vinculada a las salidas de pesca (GAC Fuerteventura, 2021).

La normativa canaria refiere tres tipos de actividades turísticas, siempre entendidas como complementarias a la pesca y acuicultura:

- "Pesca-turismo: actividad desarrollada a bordo de embarcaciones pesqueras por profesionales del sector, mediante contraprestación económica, que tiene por objeto la valorización y difusión de su trabajo en el medio marino, productos pesqueros, patrimonio y cultura y en la que los turistas embarcados no podrán ejercer la actividad pesquera.

- Turismo acuícola: actividad desarrollada por los colectivos profesionales que desarrollan la actividad de la acuicultura, mediante contraprestación económica, orientada a la valorización y difusión de la actividad acuícola, sus productos, patrimonio y cultura.

- Turismo marinero: actividad desarrollada por los colectivos de profesionales del mar, mediante contraprestación económica, orientada a la valorización y difusión de las actividades y productos del medio marino, así como de las costumbres, tradiciones, patrimonio y cultura marinera y que, por ello, trasciende de la mera actividad extractiva y comercial."

Además de hacer hincapié en el carácter complementario de estas actividades (dicta que en situaciones normales no puedan proporcionar más del $40 \%$ de los ingresos totales de los profesionales), la Ley de Pesca de Canarias prevé que deban orientarse a los objetivos de difundir el patrimonio (tradiciones, oficios, gastronomía, cultura, artes, aparejos y técnicas), la evolución social, económica y tecnológica de estas comunidades, así como las relaciones entre la conservación y las actividades humanas. Desde una perspectiva coherente, para una gestión adecuada que evite la sobreexplotación, la banalización de los referentes de identificación simbólica de las poblaciones pesqueras o la migración hacia otras actividades productivas, el foco del modelo de desarrollo habría que orientarlo hacia la preservación de los saberes tradicionales y del entorno, a través de la articulación entre los nuevos patrones laborales y el mundo de la mar. El error de no contemplar y contrarrestar la tendencia del turismo a la absorción de otros sectores, como el pesquero, podría generar el efecto contrario: la desaparición o tematización de un sector pesquero en el que la pesca pierde protagonismo frente a la performatividad de la actividad, una menor diversificación económica y una mayor dependencia turística del destino, así como una disminución de su resiliencia ante circunstancias de estrés específicas como la generada por la crisis de la COVID-19.

La normativa canaria estipula los requisitos para el desarrollo de estas actividades. Entre ellos, pueden destacarse la necesidad de disponer de las preceptivas licencias, autorizaciones y permisos, que, en caso de utilización de buques pesqueros, implica: la obligatoriedad de su inscripción en el censo correspondiente en función de la actividad; solicitud de inscripción en la tipología correspondiente de turismo pesquero; disposición de cobertura de responsabilidad civil en vigor; y el deber de elaborar memorias anuales de la actividad. Al mismo tiempo, las embarcaciones deben contar con 'medidas de seguridad y habitabilidad', si bien no se especifican cuáles, así como establecer los medios necesarios para evitar generar impactos negativos en el medio marino (especialmente en relación con la emisión de residuos, el tratamiento de las especies capturadas accidentalmente o la interacción con cetáceos o tortugas). La regulación estipula para ello las tareas de control de estos requisitos y sanciones pertinentes en caso de incumplimiento. Frente a estas específicas exigencias a 
un sector con escasa experiencia emprendedora, las compensaciones en formación y apoyo deberían encaminarse a potenciar el control de la actividad por parte de las organizaciones pesqueras, limitando los riesgos derivados de la capitalización del recurso por agentes exógenos.

\section{LA POBLACIÓN PESQUERA FRENTE AL TURISMO PESQUERO: OPORTUNIDADES Y LIMITACIONES}

Estudios previos (IEO, 2013) indicaban una enorme predisposición de los pescadores profesionales canarios hacia la implementación del turismo pesquero, aunque con ciertos recelos. Conscientes de que constituiría una actividad que pondría en valor el patrimonio pesquero tradicional y un modo de diversificación de las actividades pesqueras cuya rentabilidad reduciría la necesidad de salir a faenar y el desgaste biológico, algunos armadores habían comenzado a adecuar ciertas embarcaciones ante la posibilidad de llevar turistas a bordo.

Actualmente, los pescadores interesados en implementar la actividad consideran que el producto de pesca-turismo podría tener un atractivo mucho mayor si se permitiera que los turistas pudieran participar en las prácticas de pesca tradicional, entendiendo que una normativa más flexible, similar a la italiana, facilitaría el auge de la actividad y sus beneficios socioambientales asociados. De este modo, se alude a que la participación de los turistas en la pesca no solo constituiría un valor añadido, sino que favorecería a la diversificación económica, contribuyendo a la autoestima de los pescadores y a la disminución de la presión sobre las pesquerías. El proyecto podría potenciar el relevo generacional en el sector, que podría haber seguido faenando, contrarrestando en su medida las afecciones económicas de una excesiva orientación turística. La adecuación de tales argumentos a los de las administraciones públicas, apuntan a la apropiación estratégica de los discursos institucionales sobre la sostenibilidad socioeconómica y ambiental, redirigiéndolos en su favor. Esta práctica ha sido observada en otros contextos de conflictos de territorialización en poblaciones locales Canarias, a modo de herramienta para la legitimación de sus posturas y posicionarse en la arena de la toma decisiones en la gestión de su territorio (Díaz, 2015). Un discurso que en ocasiones llega a abarcar lo idóneo de sus justificaciones para la oferta turística general.

"Aquí, en su día, cuando se empezó con el turismo, lo que había eran barcos de pesca. La gente venía a las playas y salía con la gente de los pueblos, iban y aprendian... Y eso es lo que se pedía, un poco. Es decir, bueno, pues yo soy marinero y ¿puedo llevar a dos personas hoy y dos personas me suponen 100€? Pues eso va a repercutir en que no tengo tanta necesidad de pescar y descansan los pescaditos. ;Es compatible con algo! (...) Y, por ejemplo, a ti te dicen, tú que eres turista, "Tú que vas a ir a la mar, ¿quieres ir con un marinero profesional y quieres pasar un día...?”, "Si". No es lo mismo decir "Voy en una lancha y voy con alguien". Eso lo consigues en cualquier lado. Pero un barco de pesca, que le dices cómo se pesca, cómo tal... Y es diferente hasta en el sentido de... hasta la gente, tú conoces a la gente después y dices "Pues..." y haces lazos de unión con esa familia, con esa gente, que esa te la recomiendan a otra, llegan y los invitas a comer a la casa, tú te vas a ese país y te invitan, ese te presenta al otro y te manda al otro... y asi vamos todos creando lazos de amistad y de amigos. (...) Esos son los mejores embajadores que tenemos nosotros 
en relación al turismo. Ni son los turoperadores, ni son nada: son esa gente. Que tú llevas a 10 y 10 informan a 10.000. Y el otro informa a tal. Y esa gente ya vienen recomendados por esa gente, no por turoperadores ni por nada. Y ya vienen a tiro hecho y dejan dinero directamente aquí. (...) Lo bonito es eso, que tú tengas contacto con ellos y decir "Mira, yo no lo voy a ver cómo ganar dinero, sino como vivir y abrirme al mundo". Es decir, es una forma de vida que no es con ambición de decir "me voy a hacer rico y voy a comprar un crucero". No, es vivir y echar días para atrás y años para atrás, y conociendo gente, y enriqueciéndote en cultura, vas conociendo a otros, hablas con unos, con otros..." (Patrón mayor 2)

Incluso aquellos pescadores que no están interesados en participar del pesca-turismo, entienden el potencial de la actividad. Muchos pescadores aluden a tiempos pasados en los que los pescadores profesionales llevaban a pescar a turistas a bordo de sus embarcaciones y son conscientes de su utilidad a la hora de complementar los ingresos de los pesadores con estrategias productivas menores. Frente a ellos, aquellos profesionales más productivos (con jornadas más largas, a mayor profundidad, etc.), consideran que llevar turistas a bordo puede ser un inconveniente que dificulte su labor.

"El que vive de la pesca realmente no necesita llevar dos personas a bordo que no te den utilidad. Y luego, más que otra cosa, el estómago en la pesca cuando están en la mar. Nosotros, a veces... a los barcos más pequeños venían alemanes. Hace un montón de años se llevaban siempre a pescar. Y eso era una cosa... Y muchas veces estaban por aquí y tal... Pero es que no los podemos llevar. Mucha gente prefiere ir en un barco profesional a pescar que en un deportivo que te meten una clavada y después no... no eso. Pero yo, por ejemplo, que hago realmente la pesca a saco, a mí no me interesaría, por lo menos. A la gente, a lo mejor, que se dedica menos a la pesca o de forma más esporádica, igual sí. También puede servir para diversificar, pero ya te digo, el que se dedica a la pesca a fondo... [no le interesa]. Es que, estamos hablando de condiciones, a veces... duras. Si tú vas a meter a un turista ahi a... con 25 nudos de viento, tal... Lo tengo que volver para tierra y pierdo un día de pesca. Es que no compensa. (Pescador profesional 7)

Los resultados de las entrevistas realizadas muestran que muchos profesionales de la pesca no son plenamente conscientes del atractivo que puede tener la divulgación de otros aspectos patrimoniales de la actividad. Esto resulta coherente con la poca o nula predisposición a proponer actividades de turismo marinero (orientadas a la valorización y difusión de su actividad fuera de las embarcaciones), así como con su baja percepción de los aspectos diferenciales del pesca-turismo frente a otros tipos de actividades turísticas en embarcación. Estas consideraciones pueden ser tomadas en cuenta como una materialización de la baja valoración de las actividades relacionadas con este sector productivo, así como una consecuencia de su escasa experiencia emprendedora.

Otros profesionales, en cambio, muestran el discurso de la especificidad pesquera, tanto a la hora de faenar como por su conocimiento del medio, para legitimar su posicionamiento a favor de la compatibilización de su oficio con el turismo. Ambos aspectos pueden resultar claves para su empoderamiento y la puesta en valor de sus prácticas culturales cotidianas.

"Voy a pescar y estoy por aquella zona un día, salto para tierra, llego por la tarde, y hago mi comidita alli en tierra... pero tu pescado o cualquier cosa. (...) Y después 
tienes unos charcos, unos lagos metidos entre medias... charcones grandes. Tú llevas a turistas, a extranjeros de éstos, los metes ahi y se quedan locos.” (Patrón mayor 2)

"Y, por ejemplo, a ti te dicen, tú que eres turista, "Tú que vas a ir a la mar, ¿quieres ir con un marinero profesional y quieres pasar un día...?", "Sï". No es lo mismo decir "Voy en una lancha y voy con alguien", eso lo consigues en cualquier lado. Pero un barco de pesca, que le dices cómo se pesca, cómo tal..." (Pescador profesional 3)

El pesca-turismo podría engarzarse adecuadamente en la imagen turística del destino y su actual elenco de productos. Una parte importante de la oferta turística de la isla tiene vinculaciones importantes con el medio marino; ya sean basados en la contemplación, el consumo ocioso, el desarrollo de deportes o la observación de cetáceos, por ejemplo. Este producto podría además poner de relieve prácticas y tradiciones culturales muy relacionadas con la identidad local, lo que podría favorecer formas de desarrollo endógeno. De hecho, aunque la pesca tradicional de bajura constituya un referente identitario para la isla, su relación con el ámbito turístico es muy limitada. A pesar de que los pescadores profesionales en Canarias están constantemente rodeados de turistas y servicios orientados a ellos, parece que formen parte de otra capa de la realidad con la que sólo se interacciona superficialmente, como un componente más del paisaje.

"Aparte, me beneficio algo del turismo, porque en su día lo que dio pie a todos los puertitos marineros eran los barquitos de pesca, que iba todo el mundo en los barquitos de pesca. Y quiero decir que nosotros de la pesca, directamente del turismo no nos hemos beneficiado de nada." (Pescador profesional 5)

La baja interacción de los profesionales de la pesca con el sector turístico supone otra de las dificultades para el desarrollo del producto. El bajo conocimiento sobre el sector turístico se relaciona con limitaciones a la hora de diseñar productos atractivos adaptados a diferentes perfiles de visitantes, la interacción con los turistas en otros idiomas y las estrategias de comunicación y comercialización de sus productos. Los profesionales del sector pesquero se muestran dubitativos sobre la forma en que sus ofertas podrían llegar a la demanda, así como la gestión de esta actividad. Otorgar un papel relevante a los pescadores y la presencia de cooperativas puede ser una herramienta eficaz a la hora de plantear y publicitar ofertas, coordinar las actividades en función de la capacidad y las estrategias pesqueras de los buques, así como para tareas administrativas, financieras o comerciales. En este sentido, para aumentar las posibilidades de éxito, la actividad debería comenzar implementándose en aquellas localidades en las que ya existen cooperativas o cofradías operativas que puedan ofrecer el respaldo necesario.

La desconfianza de los pescadores canarios por el sentimiento de falta de implicación real en la toma de decisiones se relaciona con su escasa práctica emprendedora y con experiencias pasadas en las que los beneficios de implementaciones exógenas han recaído en pocas manos o directamente fuera de la comunidad (Díaz, 2015). Sus temores inciden así en la posibilidad de un esfuerzo poco reconocido que suponga, a medio plazo, abrir la puerta a perjuicios no contemplados. Esta preocupación ha sido observada en otros contextos (Herrera et al, 2015) donde la insuficiente o nula participación en los proyectos de desarrollo, la rígida burocracia y la descoordinación administrativa e institucional obstaculizan el éxito de nuevas iniciativas, al tiempo que dificultan las dinámicas de adaptación y apropiación de 
las poblaciones locales (Herrera et al, 2018; Comisión Europea, 2000). El sentimiento de imposición y de falta de transparencia, la impersonalización que implica la generalización de la normativa y la cautela ante la modificación de ciertas pautas históricas que conlleva el pesca-turismo (Lucas y Kirit, 2009; IEO, 2013; Herrera et al, 2018), pone en alerta a un colectivo que desconfía de una administración que regula su cotidianidad unilateralmente y teme los efectos de la pérdida de control sobre la actividad.

\section{CONCLUSIONES}

Frente a las consecuencias sobrevenidas de la COVID-19 el turismo se ha posicionado como uno de los sectores económicos más perjudicados. Principalmente, los destinos masivos y con mayor dependencia turística han visto afectadas sus economías. Sin embargo, a pesar de las múltiples voces que han debatido abiertamente la necesidad de un cambio de modelo y la oportunidad que supone la circunstancia actual para repensar el turismo, parece que la luz al final del túnel ilumina las intenciones de repetir las dinámicas del pasado.

En Canarias, el impacto de la pandemia ha mostrado una excesiva subordinación al turismo que apunta a la necesidad de potenciar mecanismos alternativos coherentes con la sociedad y el medio. Entre las estrategias resilientes que se pueden implementar para construir productos que disminuyan la dependencia en los destinos, el turismo pesquero, y en especial el pesca-turismo, aquel que compatibiliza la actividad pesquera profesional con actividades turísticas basadas en la apreciación y disfrute de sus prácticas tradicionales, se muestra con gran potencial para complementar y diversificar la actividad productiva de este sector específico y de los destinos de litoral en general. Por un lado, puede ser una herramienta para favorecer la calidad de vida y la autoestima de la población vinculada a la pesca a través de la puesta en valor de sus prácticas. Por otro, puede ser un factor clave para reducir la presión sobre los recursos y fomentar un turismo respetuoso con el medio y la cultura local.

Una gestión adecuada que evite la banalización de los referentes de identificación simbólica relacionados con la actividad o la absorción y performativización de la misma por los intereses turísticos, podría repercutir en la recuperación de un sector pesquero que se beneficie de la actividad turística sin abandonar su producción primaria. La diversificación económica de este modelo, no solo puede generar numerosos beneficios socioecológicos en un destino consolidado de sol y playa, sino que podría favorecer los mecanismos de resistencia socioeconómica ante posibles impactos sobrevenidos que afecten las dinámicas del sistema turístico.

\section{BIBLIOGRAFÍA}

Cañada, E. (2019) "Trabajo turístico y precariedad", en E. Cañada y I. Murray (Coords.). Turistificación global. Perspectivas críticas en turismo. Barcelona: Icaria Editorial, pp. 267-287.

Cañada, E. Murray, I. (2021) “Turistificación Confinada”, en E. Cañada \& I. Murray (Coords.) \#TourismPostCOVID-19. Turistificación Confinada. Barcelona: Alba Sud, pp. 14-80.

Centro Tecnológico Del Mar (CETMAR) (2010) "La pesca de bajura: situación en 2007 y perspectivas para una orientación sostenible". Pontevedra: Ed. CETMAR.

Comisión Europea (2003) "Rebuilding cod and hake stocks", Fishing in Europe, n¹8, Agosto.

Cornell Empowerment Group (1989) "Empowerment and family support", Networking Bulletin, 1(1): $1-23$. 
Cruz Vareiro, L. \& Cadima Ribeiro, J. (2007) "Sustainable use of endogenous touristic resources of rural areas: Two portuguese case studies", Pasos. Revista de Turismo y Patrimonio Cultural, 5(2): 193-207.

Delgada, N. (2017) “Si algún lugar debería sentir turismofobia, ese es Tenerife". Vice, en https://www.vice.com/es/article/kz7aaa/turismofobia-tenerife-espana-corrupcion. [consulta 26/05/2021]

Díaz, P. (2015) Cambio cultural e imagen turística. Efectos de los procesos de reconfiguración y consumo de imágenes proyectadas (tesis doctoral). Sevilla: Universidad Pablo de Olavide, accesible en https://rio.upo.es/xmlui/bitstream/handle/10433/2114/diaz-rodrigueztesis15.pdf?sequence=1\&isAllowed=y [consulta 27/05/2021]

Díaz-Rodríguez, M.C., Delgado-Acosta, C.R., Calero-Martín, C.G., García-Herrera, L.M., Pérez, M. y Mejías, M.A. (2002) "Ciudad oscura, ciudad luminosa. Santa Cruz de Tenerife (1980-2000)", Investigaciones Geográficas, 28: 33-51.

Dimmock, K. y Musa, G. (2015) "Scuba Diving Tourism System: A framework for collaborative management and sustainability", Marine Policy, 54, 52-58.

Doxey, G.V. (1975), "A Causation Theory of Visitor-Resident Irritants: Methodology and Research Inferences," The Impact of Tourism, Sixth Annual Conference Proceedings of The Travel Research Association Salt Lake City: Bureau of Economic and Business Research, University of Utah, p. 195.

Fernández-Latorre, F. y Díaz del Olmo, F. (2011) "Huella ecológica y presión turística socioambiental. Aplicación en Canarias", Boletín de la Asociación de Geógrafos Españoles, 57: 147173.

Fuller, R.A., Irvine, K.N., Devine-Wright, P., Warren, P.H. y Gaston, K.J. (2007) "Psychological benefits of greenspace increase with biodiversity", Biol. Letters., 3, 390-394.

García-Hernández, J.S. y Ginés de la Nuez, C. (2020) "Geografías de la desposesión en la ciudad neoliberal: ejecuciones hipotecarias y vulnerabilidad social en Santa Cruz de Tenerife (CanariasEspaña)", Revista EURE, 46(138).

García-Hernández, J.S., Armas-Díaz, A. y Díaz-Rodríguez, M.C. (2020) "Desposesión de vivienda y turistificación en Santa Cruz de Tenerife (Canarias-España): los desahucios a inquilinos en el barrio de El Toscal", Boletín de la Asociación de Geógrafos Españoles, 87. DOI: https://doi.org/10.21138/bage.2982

García-Herrera, L.M. y Sabaté-Bel, F. (2005) "Planeamiento urbano, participación ciudadana y gobernanza: el plan general de Santa Cruz de Tenerife (Tenerife, Canarias)", Scripta Nova. Revista Electrónica de Geografía y Ciencias Sociales, 9.

Gelan, A. (2003). "Impactos económicos locales. El British open". Annals of Tourism Research En Español, 5(1). Gobierno de Canarias y Exeltur. (2019). Impactur Canarias 2018. Estudio del impacto económico del turismo sobre la economía y el empleo de las Islas Canarias. Santa Cruz de Tenerife/Las Palmas de Gran Canaria.

González, E., Cárcaba, A., y Ventura, J. (2010) “The Importance of the Geographic Level of Analysis in the Assessment of the Quality of Life: The Case of Spain", Social Indicators research, 102(2): 209-228.

González, E., Cárcaba, A., y Ventura, J. (2011) "Quality of life ranking of Spanish municipalities", Revista de Economía Aplicada, 19: 123-148.

González-Morales, O., Santana-Talavera, A. y Domínguez-González, D. (2020) “The involvement of marine tourism companies in CSR:the case of the island of Tenerife", Environment, Development and Sustainability, Vol.:0123456789. DOI: https://doi.org/10.1007/s10668-020-01120-2

Gössling, S.; Scott, D. \& Hall, M. (2021) "Pandemics, tourism and global change: a rapid assessment of COVID-19", Journal of Sustainable Tourism, 29:1, 1-20

Grupo de Acción Costera Fuerteventura (GAC) (2021) Estrategia de desarrollo local participativo, en https://docplayer.es/48742961-Estrategia-de-desarrollo-local-participativa.html [consulta $15 / 03 / 2021]$

Hampton, M. (2005). "Heritage, local communities and economic development". Annals of Tourism Research, 32(3): 735-759 
Harvey, D. (2011). "Crises, geographic disruptions, and the uneven development of political responses". Econ. Geogr., 87(1): 1-22.

Herrera, P., Miret-Pastor, L y Lizcano, E. (2018) "Viajar con la tradición: Los pescadores artesanales ante la pesca-turismo en la Comunidad Valenciana (España)", Cuadernos de Turismo, DOI: https://doi.org/10.6018/turismo.41.327031

Herrera-Racionero, P., Lizcano, E. y Miret-Pastor, L. (2015) “'Us’ and 'them'. Fishermen from Gandía and the loss of institutional legitimacy", Marine Policy, 54: 130-136.

Iaquinto, B.L. (2020) "Tourist as vector: Viral mobilities of COVID-19", Dialogues in Human Geography, Jun. 2020. DOI: https://doi.org/10.1177/2043820620934250

IEO (2013) "Caracterización del Banco de La Concepción. Informe del Instituto Español de Oceanografía-Centro Oceanográfico de Canarias. LIFE+ INDEMARES". Madrid: Fundación Biodiversidad.

Jafari, J. (1994) "La cientifización del turismo", Estudios y Perspectivas en Turismo, 3(1): 7-36.

Kaplan, S. (1995) "The restorative benefits of nature: toward an integrative framework", J. Environ. Psychol., 15, 169-182

Lucas, E.Y. y Kirit, R. (2009) "Fisheries-Marine Protected Area-tourism interactions in Moalboal, Cebu, Philippines", Coastal Management, 37(5):480-490.

Machado Carrillo, A. (1990). Ecología, medio ambiente y desarrollo turístico en canarias. Santa Cruz de Tenerife: Gobierno de Canarias. Consejería de Presidencia.

Martín, J.C. y Mendoza, C. (2012) "A DEA Approach to Measure the Quality-of-Life in the Municipalities of the Canary Islands", Social Indicators research, 113(1): 335-353.

Mitchell, R. y Popham, F. (2008) "Effect of exposure to natural environment on health inequalities: an observational population study", Lancet, 372, 1655-1660.

Molina García, A. (2013) Diagnóstico estratégico de la actividad de Pesca-turismo en España. Ministerio de Agricultura, Alimentación y Medio Ambiente, Secretaría General de Pesca, Univ. Politécnica de Madrid.

Moreno Muñoz, D. (2018) “Aportación a los conceptos de turismo marinero/pesquero y pescaturismo", Cuadernos de Turismo, 42: 385-396.

Pardellas, X. y Espejo, C. (2013) “Turismo pesquero", en E.A. Del Valle Tuerro y D. López Olivares (Coords.) La actividad turística española en 2012. Madrid: Ed. Universitaria Ramón Areces, pp. 41-48.

Pardellas, X y Padín, C. (2011) "Turismo pesquero: experiencias en Europa y España”, Papeles de Economía Española, 128: 221-228.

Pardellas, X y Padín, C. (2013) "La nueva demanda combinada de turismo litoral y turismo pesquero: motivaciones y efectos", Cuadernos de Turismo, 32: 243-258.

Pascual, J. (2004) "Las investigaciones sobre la pesca en Canarias: entre las reservas marinas y las nuevas formas de pescaturismo", Pasos. Revista de Turismo y Patrimonio Cultural, 2(2): 295-306.

Rodríguez Darias, Alberto J. (2011). Turismo y áreas protegidas. Tesis Doctoral, Universidad de La Laguna.

Rodríguez Darias, Alberto J. (2020). “Algunas reflexiones sobre las implicaciones culturales de la adaptación del turismo tras la pandemia”. En Simancas Cruz, M; Hernández Martín, R. y Padrón Fumero, N. Turismo pos-COVID-19. Reflexiones, retos y oportunidades. Tenerife: Cátedra de Turismo CajaCanarias- Ashotel de la Universidad de La Laguna.

Rodríguez Darias, A.J., Díaz, P., Ruiz-Labourdette, D., Pineda, F.D., Schmitz, M.F. y Santana, A. (2010) "Selection, design and dissemination of Fuerteventura's projected tourism image (Canary Isles)", WIT Transactions on Ecology and the Environment, 130: 13-24.

Serensinhe, C.I., Preis, T. y Moat, H.S. (2015) "Quantifying the Impact of Scenic Environments on Health", Sci. Rep., 5.

Statista (2021) Índice de calidad de vida en España en 2019, por comunidad autónoma, en https://es.statista.com/estadisticas/1033520/indice-de-calidad-de-vida-por-region-en-espana/ [consulta 26/05/2021] 


\section{Breve currículo}

\section{Pablo Díaz Rodríguez}

Pablo Díaz es profesor Ayudante Doctor en el departamento de Sociología y Antropología de la Universidad de La Laguna (ULL, Tenerife). Es miembro del equipo transdisciplinar de investigación 'Sistemas socioecológicos, Paisaje y Desarrollo local (ADAPTA)' de la Universidad Complutense de Madrid, especializado en investigación ambiental y turismo como aplicaciones de la antropología y la ciencia ecológica. Desarrolla trabajos académicos y aplicados relacionados con el turismo, la socioeconomía, el medio ambiente, los procesos de patrimonialización y sus efectos socioecológicos.

\section{Alberto Jonay Rodríguez Darias}

Alberto J. Rodríguez Darias es profesor del Departamento de Sociología y Antropología de la Universidad de La Laguna. Sus líneas principales de investigación se enmarcan en el ámbito de la antropología del turismo. Ha participado en la autoría de más de 50 publicaciones de impacto desde 2007. Miembro del Grupo de Investigación Reinventur y de la Cátedra de Turismo Ashotel-CajaCanarias de la Universidad de La Laguna.

\section{Agradecimientos:}

Este trabajo se enmarca en el Proyecto "Inteligencia turística para un turismo marino responsable" (ProdID2017010128) cofinanciado por la Agencia Canaria de Investigación, Innovación y Sociedad de la Información y el Programa Operativo FEDER Canarias 20142020 . 